\title{
Transformational Leadership, Job Satisfaction and Organizational Commitment
}

\author{
Haji Mustaqim ${ }^{1 *}$, Sabri² $^{2}$, Sumardin ${ }^{3}$ \\ 1,2,3 UniversitasIbnuSina, Batam,Indonesia \\ ms.syurah@gmail.com ${ }^{1 *}$
}

\begin{abstract}
This study aims to examine the relationship between transformational leadership and job satisfaction with organizational commitment. The research subjects were 30 employees of the faculty of economics. The research data were obtained using a scale of organizational commitment, a scale of transformational leadership, and a scale of job satisfaction. Based on the results of data analysis with multiple regression, it is known that the value of $F$ regression $=24.063$ with $p=0.000(p<0.001)$ which indicates that there is a very significant positive relationship between transformational leadership and job satisfaction with organizational commitment. Thus, the hypothesis "There is a relationship between transformational leadership and job satisfaction with organizational commitment" is accepted. The coefficient of determination ( $\mathrm{R}$ square) is 0.641 which means the effective contribution of both predictors of transformational leadership and job satisfaction to the organizational commitment criterion is $64.1 \%$ while the remaining $35.9 \%$ is influenced by other variables that are not included in this research.
\end{abstract}

Keywords

Transformational Leadership, Job Satisfaction, Organizational Commitment

Article Received: 10 August 2020, Revised: 25 October 2020, Accepted: 18 November 2020

\section{Introduction}

Human resources are the most important assets in an organization, both large and small organizations, because they are the source that drives and directs the organization and maintains and develops the organization in the various demands of society and times. Employees not only take into account the reward in the form of money, but also expect a certain quality of treatment in the workplace. In addition to rewards, employees seek dignity, respect, perceived fair policies, cooperative coworkers, and fair compensation. One of the important factors influencing this decision is employee commitment to the organization[1][2]. Commitment to the organization is an aspect that plays an important role in an organization, because commitment to the organization can affect the increase in work effectiveness and efficiency[3]. Northcraft and Neale in Suyasa and Coawanta said that generally employees who have a high commitment to the organization will show maximum effort in performing their duties[4][5].

Company organizations need qualified employees who have a high level of commitment to be able to survive in a very competitive business lately. High commitment shows the willingness of employees to work hard for the company, a strong belief and acceptance of the goals and values of the company and the desire for employees to maintain their membership in the company[6]. This ideal condition is what the company aspires to do. However, the reality shows that some employees have low organizational commitment[7]. The phenomenon that occurs in connection with this organizational commitment is a sign that the company cannot meet expectations as desired by employees[8]. Therefore it will be difficult for employees to maintain their commitment when faced with other job alternatives that are more promising higher expectations[9][10]. This low employee commitment is a big loss for the company, especially if it occurs for employees who have been heavily trained by the company[11]. The problems caused by the low commitment of employees in a company cannot be separated from the role of a leader in the company. Several research results indicate that one of the factors that are considered important influencing organizational commitment is leadership (Mowday et al., In Avolioet. As part of the 
organization, leadership influences commitment through the relationship between superiors and subordinates, between employees and their leaders[12].

The main role of a leader is to influence others to voluntarily achieve predetermined goals. Leaders create visions and inspire others to achieve that vision and expand themselves beyond their normal capabilities. Sukarno Marzuki states that every leader in a work organization environment is obliged to pay serious attention to fostering, mobilizing and directing all potential employees in order to increase job satisfaction, organizational commitment, and high performance. Many leadership models, in this study focus more on the Transformational Leadership model which is seen as more complete and has many advantages, especially for organizational change. Transformational leadership is defined as a process of mutual enhancement between leaders and followers to a high level of morality and motivation. Research shows that the ability of leaders in implementing transformational leadership styles in organizations has a significant impact on organizational commitment. Another factor that is thought to have a relationship with the level of organizational commitment is job satisfaction. Job satisfaction has a positive and strong influence on organizational commitment. People who get a higher level of job satisfaction tend to feel that the level of affective commitment and normative commitment is higher, while the effect on continuance commitment is weaker[13]. Research conducted by Azeem has contributed to organizational behavior theory. This finding is very informative in explaining aspects of organizational behavior, especially the factors that contribute to employee organizational commitment. Job satisfaction was found as a predictor of organizational commitment. In this study, it was found that there was a positive relationship between job satisfaction and organizational commitment. This means that if job satisfaction increases, organizational commitment will also increase.

\section{Organizational Commitment Organizational} commitment is seen as a value orientation towards the organization that shows individuals really think about and prioritize their work and organization. Individuals will try to give everything they have in order to help the organization achieve its goals. Commitment to the organization is an attitude that describes the level of individuals taking sides and engaging with the organizations they are in and do not intend to leave[14]. Leadership according to Kreitner and Kinicki (2010) is as follows: "Influencing employees to voluntarily pursue organizational goals." This definition implies that leadership is a process of social influence in which the leader seeks voluntary participation from employees in an effort to achieve organizational goals. In line with the opinion of Greenberg and Baron leadership is a process in which one individual influences other group members towards defined group or organizational goals. Colquit, LePine, and Wesson define leadership as the use of power and influence to direct follower activities towards achieving goals. This direction can influence the interpretation of followers' incidents, the organization of their work activities, their commitment to the main goal, their relationship with followers, or their access to cooperation and support from other work units. By referring to the various opinions of these experts, it can be concluded that leadership is the ability of individuals to use their power to influence, motivate, and support efforts that allow others to contribute to the achievement of organizational goals. One approach that can be used to understand the success of leadership is by focusing on what the leader is doing. So what is meant here is the style.

Leadership style is a behavior norm that is used by a person in trying to influence the behavior of others as he wishes. The leadership style in the organization is needed to develop a conductive work environment and build a motivational climate for employees so that it is expected to produce high productivity. Transformational leadership can create something new from something old. According to Avolio\& Bruce, the practice of transformational leadership is able to bring about more fundamental changes such as changes in the values, goals, and needs of subordinates. Meanwhile, Bass argues that the concept of leadership is a combination of the 
"trait" paradigm and the contingency or dependency approach; this is often referred to as integrative psychology. Furthermore, Suseno\&Sugiyanto (2010), quoting Bruce's opinion, defines transformational leadership as a leader's ability to influence the values, attitudes and beliefs, and behavior of other leaders with a view to completing the organizational mission. Transformational leadership seeks to change the status quo and embody a certain vision of what an organization should look like. This is done by embodying the vision in members and instilling values that can bring change to the development of members and the organization. This incarnation requires a leader who is admired by his followers. This admiration occurs because of his abilities, his commendable qualities, his enthusiasm, his personal attractiveness, his rhetorical abilities, his concern for the welfare of others and the progress of the organization[15]. The conclusion that can be drawn is that transformational leadership can be interpreted as an assessment of the leader's ability to influence subordinates to raise awareness of the importance of work results, precede group interests and increase the needs of subordinates at a higher level so that a better quality of life is achieved.

Job satisfaction is a pleasant and unpleasant emotional state in looking at their job, satisfaction reflects a person's feelings about his job. Colquitt, LePine, Wesson stated that job satisfaction is the level of pleasant feelings obtained from appraising one's job or work experience. In other words, job satisfaction reflects how we feel about our work and what we think about our work. Another opinion was put forward by Kreitner and Kinicki, that job satisfaction is an affective or emotional response to various aspects of a person's job. This definition implies that job satisfaction is not a single concept, but that people can be relatively satisfied with one aspect of their job and not satisfied with one or more aspects. Employee job satisfaction is an important element in the organization. This is because job satisfaction can affect work behavior, such as being lazy, diligent, productive, etc. or having a relationship with several types of behavior that are very important in organizations. From the various views mentioned above, it can be concluded that in essence job satisfaction is the level of a person's happy feelings as a positive assessment of their work and the environment at where they work[16].

\section{Research Method}

This research is a correlational study using transformational leadership as independent variables and job satisfaction with the dependent variable being work commitment. The research subjects were employees of the faculty of economics. The total sample of 30 employees from 307 employees was who have a service period of more than three years and status as permanent employees. This study uses a scale of organizational commitment which is based on the theory of Steers (1988), which consists of aspects, namely (1) identification with the organization, (2) involvement, and (3) loyalty. Item correlation coefficient - total moves from $\mathrm{rbt}=0.369-0.906$. The reliability of 36 valid items is $(\alpha=978)$. The transformational leadership scale is prepared based on the indicators put forward by Xirasagar (2008), namely (1) charismatic, (2) inspirational, (3) intellectual stimulation. Item correlation coefficient - total moves from rbt $=0.341-0.698$. Reliability is 32 valid items $(\alpha=0.910)$. The job satisfaction scale is based on Azeem's (2010) theory, which consists of aspects, namely (1) the job itself, (2) supervision, (3) wages or salaries, (4) promotion, (5) colleagues. Item correlation coefficient - total moves from rbt $=0.321-0.834$. The reliability of 36 valid items is $(\alpha=0.946)$. Hypothesis testing uses multiple regression statistical techniques using the Statistical Program Series (SPS 2000).

\section{Results and Discussion}

From data analysis using multiple regression, the results obtained $\mathrm{F}$ regression $=24.063$ with $\mathrm{p}=$ 0.000 ( $\mathrm{p}<0.001)$. These results mean the hypothesis proposed in this study that there is a very significant positive relationship between transformational leadership and job satisfaction with organizational commitment is accepted. In 
addition, the test between each independent variable on the dependent variable of work commitment shows that: a) the partial correlation value between transformational leadership and work commitment results in $r=0.448$ and $t$ count $=2.602$ with $\mathrm{p}=0.015(\mathrm{p}<0.005)$. These results indicate that the hypothesis that there is a positive relationship between transformational leadership and organizational commitment is accepted. b). The partial correlation value between job satisfaction and work commitment results is obtained from $r=0.707$ and $t$ count $=5.200$ with $p=0.000(p<0.001)$. These results indicate that the hypothesis that there is a positive relationship between job satisfaction and organizational commitment is accepted. c). The effective contribution of the two variables between transformational leadership and job satisfaction on organizational commitment is $64.1 \%\left(\mathrm{R}^{2}=0.641\right)$. The effective contribution of transformational leadership (X1) to organizational commitment (Y) $=16.90 \%$, while the effective contribution of job satisfaction (X2) to organizational commitment $(Y)=47.20 \%$.

\section{Discussion}

Based on the results of the research as described above, the first hypothesis in this study which states that there is a relationship between transformational leadership and job satisfaction with organizational commitment can be proven. Simultaneously it was found that there was a very significant relationship between transformational leadership and job satisfaction with organizational commitment. Therefore, it can be concluded that transformational leadership and job satisfaction are systematically related to organizational commitment. The two variables of transformational leadership and job satisfaction respectively have an effective contribution $\left(\mathrm{R}^{2}\right)$ of $16.90 \%$ and $47.20 \%$, so that the effective contribution of the two independent variables is $64.1 \%$ while the remaining $35.9 \%$ is influenced by other variables not included in this study. Several other studies have shown that there are variables related to organizational commitment. Research conducted by MiftahunNi'mahSuseno and Sugiyanto (2010) shows that there is an effect of work motivation on organizational commitment.
Chaterina Melina Taurisa and IntanRatnawati (2012) stated that in their research there is a direct influence between organizational culture and organizational commitment. This shows that the stronger the organizational culture, the higher the organizational commitment. The results of this study are in accordance with the theoretical basis that has been previously described. The behavior of a good boss or leader is one that can be used as a role model, can guide, supervise and protect subordinates. Transformational leadership is described as a form of leadership that can increase organizational commitment. Commitment can be born by applying a transformational leadership style because with this style a climate that is conducive to the development of innovation and creativity emerges.

Transformational leadership has been shown to be able to bring about more basic changes, such as changes in the values, goals and needs of subordinates and these changes have an impact on the emergence of commitment, because of the fulfillment of higher needs (Rizadinata and Suhariadi, 2013). Transformational leaders are charismatic leaders who have a major influence on their followers. Charismatic leader, is a leader who is able to generate strong emotions. Leaders are identified by being used as role models by their subordinates, can be trusted, respected, and have a clear vision and mission, which according to the perceptions of their subordinates can be realized (Bass, in Suseno and Sugiyanto, 2010) In fact transformational leadership is able to produce higher organizational commitment because of leadership. transformational is able to motivate subordinates to be more involved in their work. Transformational leadership influences commitment without the use of rewards or punishments.

Transformational leadership directly affects the level of employee participation in creating the survival of the company so that it affects commitment, namely the desire of employees to stay and work and devote themselves to the company (Silalahi, 2008). Job satisfaction has a positive and strong influence on organizational commitment. Employees who get a higher level of job satisfaction tend to feel a high level of 
affective commitment and normative commitment (Wibowo, 2013). In line with Chang \& Lee's opinion (Parwita, 2013) explained that employees who have met their intrinsic satisfaction will show high concern for the company where they work. In fact, it was found that there is a positive relationship between job satisfaction and organizational commitment. This shows that if the level of job satisfaction is high, the level of commitment to the organization will also be high. In other words when a person's job satisfaction increases as soon time their organizational commitment will also increase. The logical explanation that can be drawn from this study is that organizational commitment is a function of job satisfaction (Parwita, 2013).

\section{Conclusion}

Based on the results of data analysis from research that has been conducted on employees of the faculty of economics at Gresik, it can be seen that there is a very significant positive relationship between transformational leadership and job satisfaction with organizational commitment, while individually there is a positive relationship between transformational leadership and organizational commitment, and there is a significant positive relationship between job satisfaction and organizational commitment.

\section{References}

[1] A. Judkrue, "The transformational leadership factors influence global leaders," 2012 E-leadersh. Conf. Sustain. e-Government e- Bus. Innov. E-leadersh. 2012, 2012, doi: 10.1109/eLeadership.2012.6524708.

[2] Z. Wang, X. Li, and K. Shi, "The relationship among transformational leadership, work engagement, and emotional labor strategy," Proc. - 2010 IEEE 2nd Symp. Web Soc. SWS 2010, pp. 554-558, 2010, doi: 10.1109/SWS.2010.5607387.

[3] K. Mahmood, Z. Nayyar, and H. Mushtaq, "Role of transformational leadership on egovemment switching: Multi-channel and digital divide," 2017 12th Int. Conf.
Internet Technol. Secur. Trans. ICITST 2017, pp. 475-478, 2018, doi: 10.23919/ICITST.2017.8356453.

[4] J. Ge, X. Tian, and Q. Fu, "The mechanism of how transformational leadership impacts on subordinates' voice behavior: A test of basic assumption of affective events theory," Proceeding 2012 Int. Conf. Inf. Manag. Innov. Manag. Ind. Eng. ICIII 2012, vol. 2, pp. 243-246, 2012, doi: 10.1109/iciii.2012.6339823.

[5] $\mathrm{X} . \mathrm{Wu}$ and $\mathrm{Z}$. $\mathrm{Wu}$, "The impact of transformational leadership on individual and team performance: Evidence from knowledge work teams," 2007 Int. Conf. Wirel. Commun. Netw. Mob. Comput. WiCOM 2007, pp. 4431-4434, 2007, doi: 10.1109/WICOM.2007.1094.

[6] N. A. Said and R. Munap, "Job characteristics and job satisfaction: A relationship study on supervisors performance," 5th IEEE Int. Conf. Manag. Innov. Technol. ICMIT2010, pp. 714-719, 2010, doi: 10.1109/ICMIT.2010.5492732.

[7] I. Aouadni, A. Rebai, N. Christodoulakis, and Y. Siskos, "University teachers' job satisfaction: The MUlti-criteria Satisfaction Analysis (MUSA) method," 2013 Int. Conf. Control. Decis. Inf. Technol. CoDIT 2013, pp. 923-926, 2013, doi: 10.1109/CoDIT.2013.6689666.

[8] P. W. Liao, F. H. Wen, and C. C. Yu, "Job characteristics, work commitments, and job satisfaction of the Thai workers in Taiwan's construction industry: Taiwan Using Type A and B personalities as moderators," IEEM2010 - IEEE Int. Conf. Ind. Eng. Eng. Manag., pp. 2273-2277, 2010, doi: 10.1109/IEEM.2010.5674271.

[9] Q. Zhou, "The impact of job satisfaction affect on turnover intention: An empirical study based on the circumstances of China," ETT 2009 - 2009 2nd Int. Conf. Educ. Technol. Train., pp. 220-223, 2009, doi: 10.1109/ETT.2009.80.

[10] P. K. Lin, B. T. N. Pham, S. Y. Li, and P. C. Lin, "Impacts of leadership styles, job satisfaction, and job characteristics on public servants' organizational commitment," 2015 12th Int. Conf. Serv. 
Syst. Serv. Manag. ICSSSM 2015, 2015, doi: 10.1109/ICSSSM.2015.7170256.

[11] J. L. Xing, "Talents maintaining strategies of private enterprises based on organizational commitment," 2010 Int. Conf. Netw. Digit. Soc. ICNDS 2010, vol. 1, pp. 44-46, 2010, doi: 10.1109/ICNDS.2010.5479232.

[12] N. S. Yusoff, "Commitment in Malaysia," no. April, pp. 1-4, 2012.

[13] D. Wang and D. D. Zhang, "Relationship among organizational support, organizational commitment and organizational citizenship behavior of university faculty members," 2010 Int. Conf. Manag. Sci. Eng. ICMSE 2010, pp. 1769-1775, 2010, doi: 10.1109/ICMSE.2010.5720019.

[14] X. B. Luo, C. F. Lu, and Q. P. Luo, "Research on organizational commitment status quo of P.E teachers in general universities and colleges," 2009 Second ISECS Int. Colloq. Comput. Commun. Control. Manag. CCCM 2009, vol. 1, pp. 479-482, 2009, doi: 10.1109/CCCM.2009.5268077.

[15] S. Sattavorn, "The impact of career satisfaction, commitment and supervisory support on organizational commitment of Thai Employees: A study in Japanese subsidiaries," Proc. 2018 5th Int. Conf. Bus. Ind. Res. Smart Technol. Next Gener. Information, Eng. Bus. Soc. Sci. ICBIR 2018, pp. 344-349, 2018, doi: 10.1109/ICBIR.2018.8391219.

[16] M. Syuaib, B. H. Hayadi, and U. I. Sina, "EFFECT OF WORK CULTURE, WORK ENVIRONMENT , EMPLOYEE EMPOWERMENT AND WORK MOTIVATION ON EMPLOYEES PERFORMANCE IN EMPOWERMENT DEPARTMENT OF COMMUNITY , MARKET , COOPERATIVES AND SMALL AND MEDIUM," vol. 29, no. 6, pp. 7039-7049, 2020. 